\title{
A Taste for Transit? Analyzing Public Transit Use Trends among Youth
}

\author{
Anne E. Brown, Evelyn Blumenberg, and Brian D. Taylor \\ UCLA Luskin School of Public Affairs \\ Kelcie Ralph \\ Edward J. Bloustein School of Planning and Public Policy, Rutgers University \\ Carole Turley Voulgaris \\ UCLA Luskin School of Public Affairs
}

\begin{abstract}
In the past decade, there has been much talk about a decline in driving among youth. This study examined whether this decline is associated with an increased reliance on public transit. To address this issue, 2001 and 2009 National Household Travel Survey (NHTS) data were used to analyze the relationship between age and transit use. Findings indicate that although young adults are more likely to ride transit than older adults, transit use among youth can be explained largely by (1) life cycle factors common among young people but unlikely to persist as they age, (2) higher levels of transit use among non-whites, who are disproportionately young, and (3) locational factors such as living in densely-developed neighborhoods that may or may not continue as young people age. Therefore, whereas transit habits established early in life may persist as young adults age, the data examined here suggest that such an outcome is far from assured.
\end{abstract}

Keywords: Millennials, transit use, travel behavior

\section{Introduction}

Over the past decade, there has been much talk about a decline in auto travel among youth. Per-capita driving in the U.S. has dipped, with higher than average declines among teens and young adults (or Millennials, those born between 1980 and 2004), prompting some observers to conclude that youth are "ditching" cars for a more multimodal lifestyle that includes a greater reliance on public transit among other non-auto modes (Ball 2014; Blumenberg et al. 2012; Davis, Dutzik, and Baxandall 2012; Malcolm 2014; McDonald 2015). For example, a recent report published by the TransitCenter (2014) concludes, "The Millennial generation seems to be defying its sheltered, suburban upbringing by delaying the acquisition of a driver's license and choosing transit. Meanwhile, Baby Boomers, who grew up using transit and 
were encouraged to do so, are defying their upbringing by avoiding transit now" (TransitCenter 2014, 7).

These trends and conclusions have led to calls for a wholesale shift in transportation infrastructure investments away from new highways toward public transit to better reflect the changing tastes and preferences of young travelers (Inglis and Baxandall 2014). But how, exactly, does age relate to transit use? Will increased transit use among young people persist as youth age into adulthood? In this study, these questions were investigated using data from the 2001 and 2009 National Household Travel Survey (NHTS). First, trends in transit use among young adults from 2001 to 2009 were analyzed, and then a cohort model was developed to examine whether young adults are more likely than older adults to (1) use transit on the survey day and (2) ride transit at least once over the course of a month, controlling for other determinants of transit use (such as individual and household characteristics and the character of the neighborhoods in which they live). In each of these models, the relative influence of cohort effects (birth decade), life cycle effects (such as being a student or having children), or period effects (such as the Great Recession) was assessed. These are important distinctions, because cohort effects tend to persist as the members of a generation age, whereas life cycle effects tend to rise and fall as people move from one life stage to another, and period effects may be short-lived. Distinguishing how these three effects influence transit use among young people will yield insights on whether the Millennial generation's transit use patterns observed in the 2000 s are likely to persist in the decades ahead.

The data on neighborhood characteristics and transit availability are uniquely well-suited for investigating these questions, as data were drawn from the Environmental Protection Agency's (EPA) Smart Location Database (SLD) and the U.S. Census to develop a transit supply index to measure transit richness for nearly every census tract in the U.S.

\section{Millennials and Public Transit-What Do We Know?}

Whereas America's youth are discussed under many guises, the terms "youth," "young adults," and "Millennials" are used interchangeably to refer to those born between 1980 and 2004. Recent research finds that Millennials have a heightened interest in alternative modes of travel, including public transit (Dutzik and Baxandall 2013; TransitCenter 2014), and a growing attraction to highly-urbanized metropolitan areas and neighborhoods in which transit service tends to be most extensive (Urban Land Institute and Belden Russonello Strategists [ULI/BRS] 2013).

Indeed, young adults (under age 30) are more likely to use public transit than older adults and are more enthusiastic about doing so (American Public Transportation Association [APTA] 2015a; McDonald 2015; Rosenbloom and Fielding 1998; TransitCenter 2014). In a recent ULI survey of community attribute preferences, $39 \%$ of Millennials (ages 18-36) stated that convenient public transit was important to them, compared to $29 \%$ of Baby Boomers (ages 50-68), and 25\% of Generation X (ages 37-49) (ULI 2015).

What factors might explain young adult use of and enthusiasm for public transit? Certainly, costs loom large in making mode choice decisions (Blumenberg et al. 2012; 
Frank et al. 2008; Rodríguez and Joo 2004). Teens and young adults tend to have less human capital (education and work experience) and correspondingly lower incomes than older adults, which makes younger travelers more sensitive to the high price of transportation options such as car ownership and driving. The personal income of young people tends to increase sharply during their 20s and early 30s (American Community Survey 2008-2012), as does driving (Blumenberg et al. 2012). In APTA's survey of adults ages 22-34, more than half of those who traveled by bus stated that it was "an affordable option for me" (APTA 2013).

Beyond affordability, Millennials may see other personal and societal benefits to using public transit, including the ability to engage in digital socializing while traveling, connecting with their communities, working en route, and reducing the environmental footprint of their travel (APTA 2013). However, findings on how attitudes of public transit vary by age and the effects of age-related attitudes of transit use are ambiguous. For example, the Pew Research Center (2010) finds that Millennials are slightly less likely to exhibit environmentally-conscious behaviors compared to adults in the Generation $X$ and Baby Boomer cohorts. The private subscription car-sharing service Zipcar conducts an annual survey of the attitudes of 18-34 year olds and finds that all urban residents (regardless of age) feel equally strongly about protecting the environment; however, the percentage of those concerned about the environment is substantially higher among city dwellers than among suburban and rural residents (KRC Research 2015). Finally, with respect to technology, researchers do not find a statistically-significant relationship between "a desire to stay connected through communication technologies" and transit use (TransitCenter 2014).

Residential location choices also may explain why youth are more likely than older adults to use public transit. In general, there is a positive and statistically-significant relationship between residential location and transit use, although the causal arrow may run in both directions. First, people who need to travel by public transit (due to low income, physical disability, reluctance to drive, etc.) are likely to locate in neighborhoods in which transit service is good and easy to use. For example, research has shown that low-income households without automobiles tend to be more likely to reside in transitrich neighborhoods where they can get around more easily using public transit (Glaeser, Kahn, and Rappaport 2008). Although less important than other neighborhood qualities, convenient public transit scores high among the community attribute priorities of low-income households-41\% consider it a top or high priority (ULI 2015). As noted above, cost likely plays an important role in the mode choice decisions of youth. Almost $30 \%$ of youth ages $16-25$ live in households below the poverty line, and almost half live in households below $200 \%$ of the poverty line.

For many of the reasons noted above, Millennials may prefer to travel by public transit and, therefore, to live in places where they can more easily do so. Public transit and transit-oriented development (TOD) are central to more urbanized lifestyles. There is some evidence that highly-educated youth - those who are most likely to have a choice in choosing where to live-are slightly more likely to live in urban neighborhoods today than in years past (Cortright 2015; Kolko 2015). Further, two to three times as many 
youth (under age 30 ) as adults (age 30+) report that their "ideal" neighborhood type is in an urban area-either downtown areas with a mix of land use or urban residential neighborhoods (TransitCenter 2014). Similarly, a Nielson (2014) report finds that $62 \%$ of Millennials prefer to live in urban mixed-use communities in close proximity to a diverse set of destinations.

Recent research suggests that driving among Millennials has been back on the rise in the years following the Great Recession (Thompson 2015), suggesting that period or cyclical economic factors, rather than a shift in values and preferences, may explain most of the observed decline in driving among youth (Blumenberg et al. 2012). Another recent study finds that the observed decline in youth driving has not been accompanied by a corresponding increase in travel by non-auto modes (McDonald 2015).

Finally, although transit plays a significant role in the centers of the oldest and largest U.S. metropolitan areas, particularly metropolitan New York, the aggregate role of public transit in American life and travel is a small one. Public transit accounted for less than $2 \%$ of all person-trips nationwide in 2009 . Nationally, there are approximately 43 person-trips by private vehicle for each transit trip, and even in metropolitan areas with populations over 3 million, which are, by far, transit's richest markets, the ratio of car to transit trips is still 19:1 (APTA 2012; NHTS 2009; Santos et al. 2011).

So what is the relationship between age and transit use? The literature presents conflicting stories.

\section{Data and Methodology}

Data from the 2001 and 2009 NHTS were used to analyze transit use over time. Whereas the NHTS includes limited information on stated attitudes and preferences, such as views on safety and the price of travel, it does not directly query respondents on their normative views of public transit, which can help to explain people's propensity to take transit (Bamberg, Ajzen, and Schmidt 2003). In lieu of stated preferences about transit, the paper focuses on revealed preferences through an analysis of travel behavior. Two outcome measures of transit use were considered - the percent of adults (ages 16+) who (1) used public transit on the survey day and (2) used transit in the past month. Then, a set of statistical models was estimated to assess the influence of three types of effects on the transit outcome measures.

Life cycle effects are characteristics associated with particular stages of the life cycle and typically do not "follow" people through the various stages of life (e.g., the presence of children or being a student). The second type of effect considered are period effects, which are observable across the two study years, 2001 and 2009. Period effects are events such as an economic recession that affect all population groups. ${ }^{1}$ For example, the Great Recession as a period effect is evident in falling employment rates across

\footnotetext{
${ }^{1}$ However, period effects may affect one population group more than others. For example, the recession-a period effect-may have had a larger negative effect on the employment of youth than older adults since, on average, they have less human capital.
} 
older cohorts between 2001 and 2009. ${ }^{2}$ Finally, cohort effects are the opposite of life cycle effects in that they "follow" groups of similarly-situated people through time. For this analysis, we were particularly interested in whether younger generational cohorts of travelers are more likely to use transit than those in older cohorts who, once accustomed to driving, remain reliant on automobiles as they age. The NHTS data are cross-sectional and do not follow the same individuals over time, so we were not able to directly analyze the behavior of travelers as they age. To work around this data limitation, data were included from both survey years and a series of decade-of-birth (cohort) variables was introduced. Because the sample was restricted to ages 16 and up, the 1990s birth cohort is included only in the 2009 dataset. Thus, the coefficients associated with the 1990s birth decade were interpreted with some caution. Table 1 displays descriptive statistics for the variables included in the model by birth decade cohort and survey year.

TABLE 1. Characteristics of Sample Population in 2001 and 2009

\begin{tabular}{|c|c|c|c|c|c|c|c|c|c|c|}
\hline \multirow[b]{3}{*}{ Variables } & \multicolumn{5}{|c|}{2001} & \multicolumn{5}{|c|}{2009} \\
\hline & \multicolumn{5}{|c|}{ Birth Decade Cohort } & \multicolumn{5}{|c|}{ Birth Decade Cohort } \\
\hline & $1910 s-1950 s$ & 1960s & 1970s & 1980s & 1990s & $1910 s-1950 s$ & $1960 s$ & 1970s & $1980 s$ & 1990s \\
\hline \multicolumn{11}{|l|}{ Dependent Variables } \\
\hline$\%$ ride transit on travel day & $4.0 \%$ & $5.0 \%$ & $7.2 \%$ & $7.4 \%$ & - & $4.0 \%$ & $4.5 \%$ & $5.3 \%$ & $6.4 \%$ & $6.5 \%$ \\
\hline$\%$ use transit last month & $15.3 \%$ & $18.9 \%$ & $23.9 \%$ & $27.4 \%$ & - & $13.5 \%$ & $16.5 \%$ & $18.5 \%$ & $22.4 \%$ & $24.9 \%$ \\
\hline \multicolumn{11}{|l|}{ Independent Variables } \\
\hline \multicolumn{11}{|l|}{ Race/Ethnicity } \\
\hline$\%$ Non-Hispanic White & $77.3 \%$ & $69.8 \%$ & $63.5 \%$ & $66.2 \%$ & - & $72.9 \%$ & $70.2 \%$ & $62.6 \%$ & $63.5 \%$ & $66.3 \%$ \\
\hline$\%$ Non-Hispanic Black & $11.5 \%$ & $10.4 \%$ & $11.7 \%$ & $14.0 \%$ & - & $13.5 \%$ & $9.8 \%$ & $11.4 \%$ & $10.5 \%$ & $12.5 \%$ \\
\hline \% Hispanic & $7.1 \%$ & $14.0 \%$ & $19.0 \%$ & $15.1 \%$ & - & $9.5 \%$ & $14.8 \%$ & $19.3 \%$ & $19.1 \%$ & $15.7 \%$ \\
\hline$\%$ Other & $4.0 \%$ & $5.8 \%$ & $5.8 \%$ & $4.7 \%$ & - & $4.0 \%$ & $5.2 \%$ & $6.8 \%$ & $6.8 \%$ & $5.5 \%$ \\
\hline \% Employed & $57.3 \%$ & $85.1 \%$ & $83.8 \%$ & $63.7 \%$ & - & $51.1 \%$ & $79.6 \%$ & $78.1 \%$ & $70.6 \%$ & $42.2 \%$ \\
\hline \% Student & $0.4 \%$ & $1.3 \%$ & $7.4 \%$ & $44.4 \%$ & - & $0.2 \%$ & $0.8 \%$ & $2.6 \%$ & $12.1 \%$ & $53.4 \%$ \\
\hline$\%$ Live w/kids & $31.2 \%$ & $62.9 \%$ & $36.7 \%$ & $4.6 \%$ & - & $22.0 \%$ & $58.4 \%$ & $45.4 \%$ & $8.9 \%$ & $0.5 \%$ \\
\hline$\%$ Live w/parents & $0.0 \%$ & $4.8 \%$ & $15.0 \%$ & $67.9 \%$ & - & $0.0 \%$ & $0.8 \%$ & $9.2 \%$ & $46.9 \%$ & $88.0 \%$ \\
\hline Mean household size & 2.6 & 3.6 & 3.3 & 4.0 & - & 2.3 & 3.4 & 3.6 & 3.6 & 4.2 \\
\hline Mean residential density & 3.3 & 4.1 & 4.7 & 3.4 & - & 3.5 & 3.3 & 4.4 & 3.7 & 3.4 \\
\hline Mean transit supply index & 0.4 & 0.5 & 0.7 & 0.4 & - & 0.4 & 0.5 & 0.6 & 0.5 & 0.3 \\
\hline $\mathrm{N}$ & 74,992 & 22,513 & 14,845 & 17,696 & - & 174,369 & 43,157 & 25,952 & 15,389 & 11,875 \\
\hline
\end{tabular}

The model also included data on travelers' residential neighborhood characteristics. We controlled for residential density, which numerous studies associate with transit use (Dittmar and Ohland 2004; Guest and Cluett 1976). Finally, a measure of the relative

\footnotetext{
${ }^{2}$ Interestingly, a higher share of the 1980s cohort was employed in 2009 during the Great Recession than in 2001. But this is almost certainly due to life cycle effects trumping period effects. For example, between 2001 (when the youngest members of this cohort were age 12) and 2009 (when the youngest members were age 20), many individuals in the 1980 s cohort aged into employment. Correspondingly, the share of the student population in the 1980s birth cohort declined from $44 \%$ in 2001 to $12 \%$ in 2009 .
} 
supply of public transit in the neighborhood in which respondents live was included. Although transit supply is, to some extent, endogenous to transit demand (Taylor et al. 2009), in this context, the transit supply variable could be viewed as an attribute in residential neighborhood location decisions. ${ }^{3}$ Whether the decision to locate in transit-rich or transit-poor neighborhoods reflects life cycle or cohort preferences is uncertain. If people are more likely to live in transit-rich urban neighborhoods when they are young and single, but then are also more likely to move to auto-oriented suburban neighborhoods when they marry and have children, the neighborhood choice would be a life cycle effect. In contrast, if Millennial preferences for transit-rich urban neighborhoods persist as young adults age, then neighborhood choice would be a cohort effect.

To develop the transit supply measure, data from the EPA's SLD and the U.S. Census ${ }^{4}$ were used. Transit frequency in the SLD is measured as the "aggregate frequency of transit service within a 0.25 -mile radius of a block group boundary per hour during evening peak period" (EPA 2014). In other words, it is measured as the number of vehicles per hour of service per square mile. The measure is less intuitive than other measures (e.g., proximity to a bus stop) and, therefore, should be interpreted as a composite transit service index that captures both the presence and frequency of fixedroute transit service. ${ }^{5}$

The SLD transit supply metric is based on General Transit Feed Specification (GTFS) data. Although GTFS data are available for many transit agencies, not all transit operators collect and report them. Therefore, many places that host public transit service were excluded from the database. To correct for these missing transit data, transit supply for nearly every U.S. Census tract was predicted in an effort that, to our knowledge, has not been previously undertaken for the entire United States. Predicted transit supply was calculated first by selecting variables from the American Community Survey (ACS) and U.S. Census that correlate strongly with reported transit frequency in places in which we had complete transit service data. These data then were used in an ordinary least squares regression model estimated to predict transit supply. The transit supply estimation model predicts approximately $44 \%$ of the variance observed in transit frequency $\left(R^{2}=0.44\right)$ across tracts with "full" transit data. The model estimates then were used to predict transit frequency for all census tracts in the country, including those for which we had full data. To validate the results, the actual transit service values from the SLD were compared to our predictions. The predicted transit supply levels

\footnotetext{
${ }^{3}$ Because transit supply is, at least partially, endogenous to transit demand, we ran each of the models with and without the transit supply variable. We kept the transit supply variable in the final set of models, given its significance. We note that when the transit supply variable was omitted from the models, the relationships between the dependent and independent variables remained much the same in terms of sign and magnitude. These results are available from the authors upon request.

${ }^{4}$ The EPA's SLD includes more than 90 variables summarizing urban characteristics including housing density, land use, neighborhood design, demographics and employment, and destination accessibility. It also includes data on transit supply at the block group level.

${ }^{5}$ As noted in the SLD User Guide (Ramsey and Bell 2014), the transit data are based on GTFS, a reporting format used by many large transit agencies. The data, therefore, represent the supply of fixed-route transit service. Many tracts without fixed-route transit service still may be served by paratransit.
} 
were moderately right-skewed, which was to be expected since some of the tracts with partial data may have greater transit frequency than reported in the SLD. The robustness of this predicted transit supply measure was tested by running the models described below for the tracts for which we had full transit supply data-once with the actual data and again with the predicted data. The model results varied little between the two data sources, supporting the use of the estimated transit service supply data in the tracts for which we did not have complete data.

As the map in Figure 1 shows, the vast majority of census tracts with transit service are concentrated in the very largest Metropolitan Statistical Areas (MSAs). Although the top 10 MSAs comprise about one-quarter of census tracts in the nation, they account for fully $95 \%$ of all census tracts with fixed-route public transit service; metropolitan New York alone accounts for $31 \%$ of these transit supply tracts. In addition to the highly-skewed distribution of transit service across metropolitan areas, transit service supply varies substantially across neighborhoods within metropolitan areas as well. To show this, we drew on a neighborhood typology developed in Blumenberg et al. (2015) to analyze transit supply across seven distinct types of neighborhoods, as listed and described in Table 2.

\section{United States}

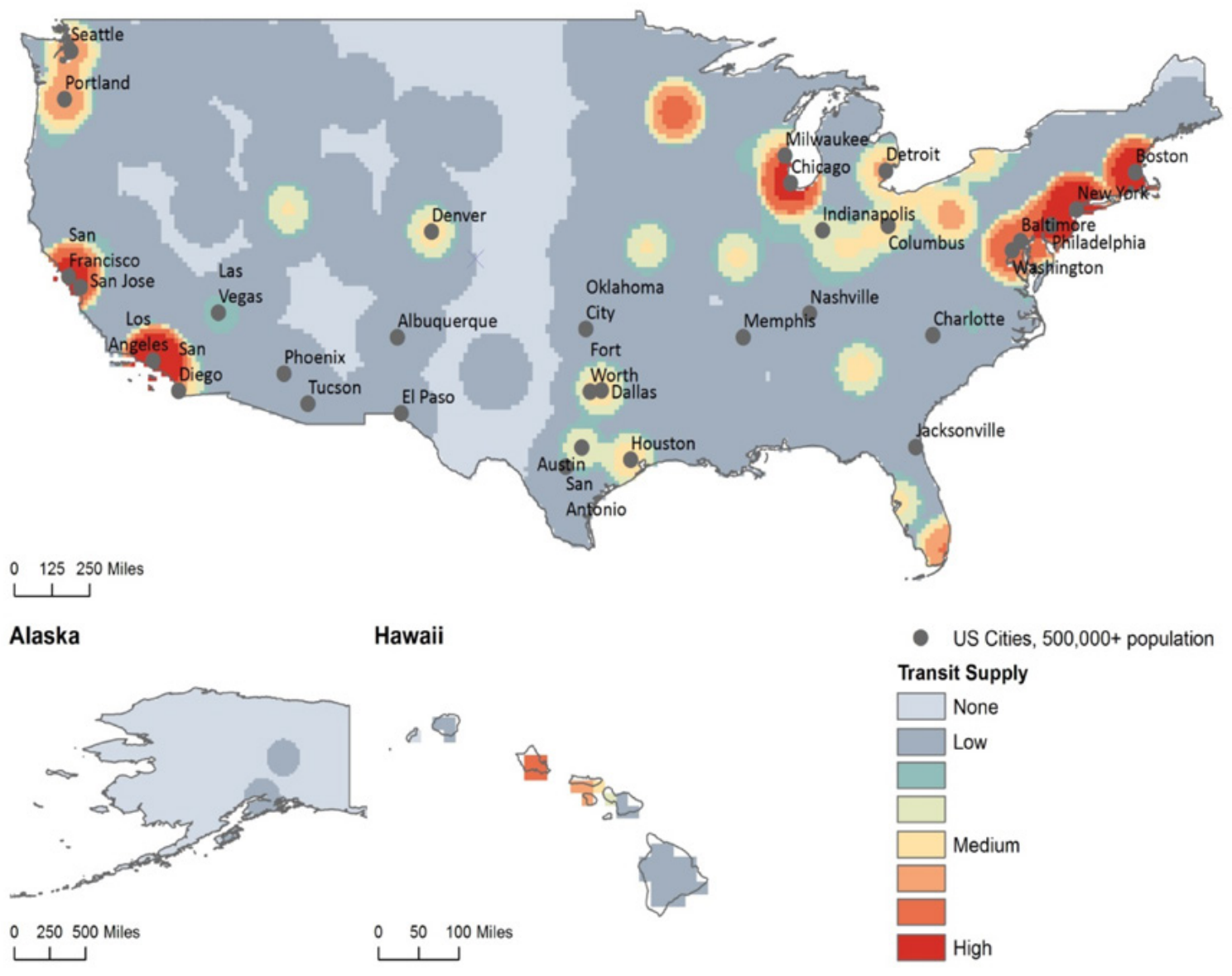

FIGURE 1. Map of U.S. transit supply 
TABLE 2. Neighborhood Types

\begin{tabular}{|c|c|c|c|}
\hline & Neighborhood Type & Neighborhood Description & Typical Location \\
\hline 1 & Mixed-use & $\begin{array}{l}\text { Mostly downtowns, plus major outlying office/ } \\
\text { industrial districts }\end{array}$ & \multirow{3}{*}{$\begin{array}{l}\text { Urban-type } \\
\text { neighborhoods }\end{array}$} \\
\hline 2 & Old Urban & Densest, least auto-oriented neighborhoods & \\
\hline 3 & Residential Urban & Mostly central city residential areas & \\
\hline 4 & Established Suburban & Mostly older suburban residential areas & \multirow{3}{*}{$\begin{array}{l}\text { Suburban-type } \\
\text { neighborhoods }\end{array}$} \\
\hline 5 & Suburban Patchwork & Largely mixed commercial and residential areas & \\
\hline 6 & New Development & Typically newest, most sprawling developments & \\
\hline 7 & Rural & & Rural areas \\
\hline
\end{tabular}

As Figure 2 shows, the transit supply index is, by far, the highest in "Old Urban" neighborhoods that are among the most densely-developed in the country, but which comprise only $4 \%$ of all U.S. census tracts. In contrast, three in five $(6 \%)$ census tracts in the U.S.-largely in rural and outlying suburban areas-have little or no transit service.

FIGURE 2.

Transit supply in U.S. by neighborhood type

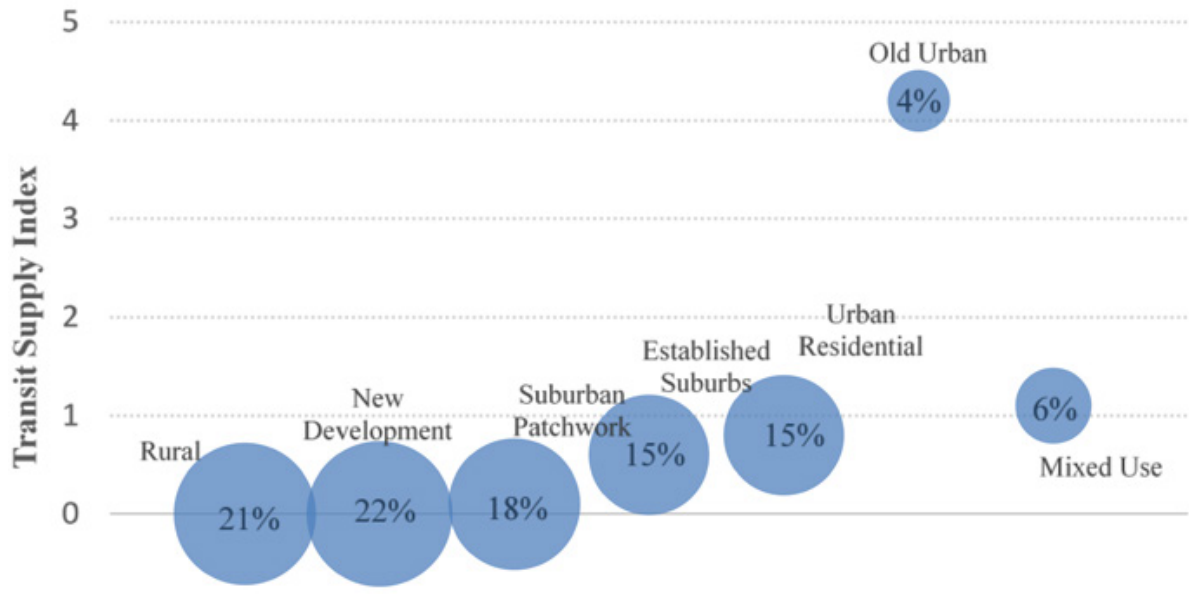

\section{How Does Transit Use Vary by Age?}

The two figures below reveal four distinct transit use patterns. First, Figure 3, which displays the percentage of the survey population that used transit on the previous day, shows that transit is used by a small share of the U.S. population, less than $8 \%$ (age 16 older) used transit on the survey day.

Figure 4 is similar to Figure 3, but shows whether respondents used transit at all over the previous one or two months. ${ }^{6}$ The two graphs viewed together suggest a second pattern - that people report "occasionally" using public transit far more than they report using it on the "previous day." The two figures collectively reveal a third pattern: teens and young adults ride public transit much more frequently than older adults.

\footnotetext{
${ }^{6}$ The NHTS includes a survey question intended to capture those travelers who ride transit only occasionally. Unfortunately, the question differs between the two survey years. In 2001, respondents were asked whether they used transit in the previous two months, whereas in 2009 they were asked whether they used transit in the last month, making it difficult to compare results directly across the two survey years.
} 
In general, transit use tends to increase from the teens into the mid-20s, but then declines until about age 70.? The fact that this same pattern is seen in both survey years suggests a likely life cycle effect on transit use, whereby transit use declines after the mid-20s as people move through various stages of the life cycle.

FIGURE 3.

Percentage using transit on survey day by age and year

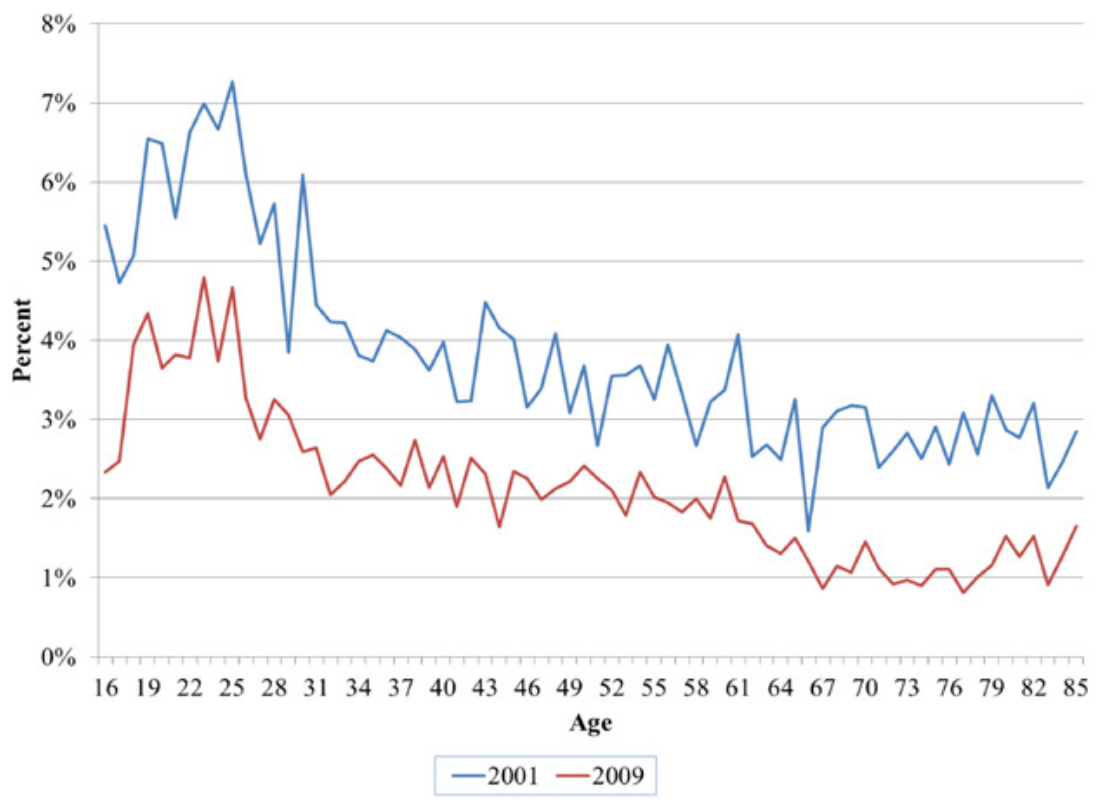

Source: NHTS, 2001 and 2009

\section{FIGURE 4.}

Percentage using transit in the last $1-2$ month(s)

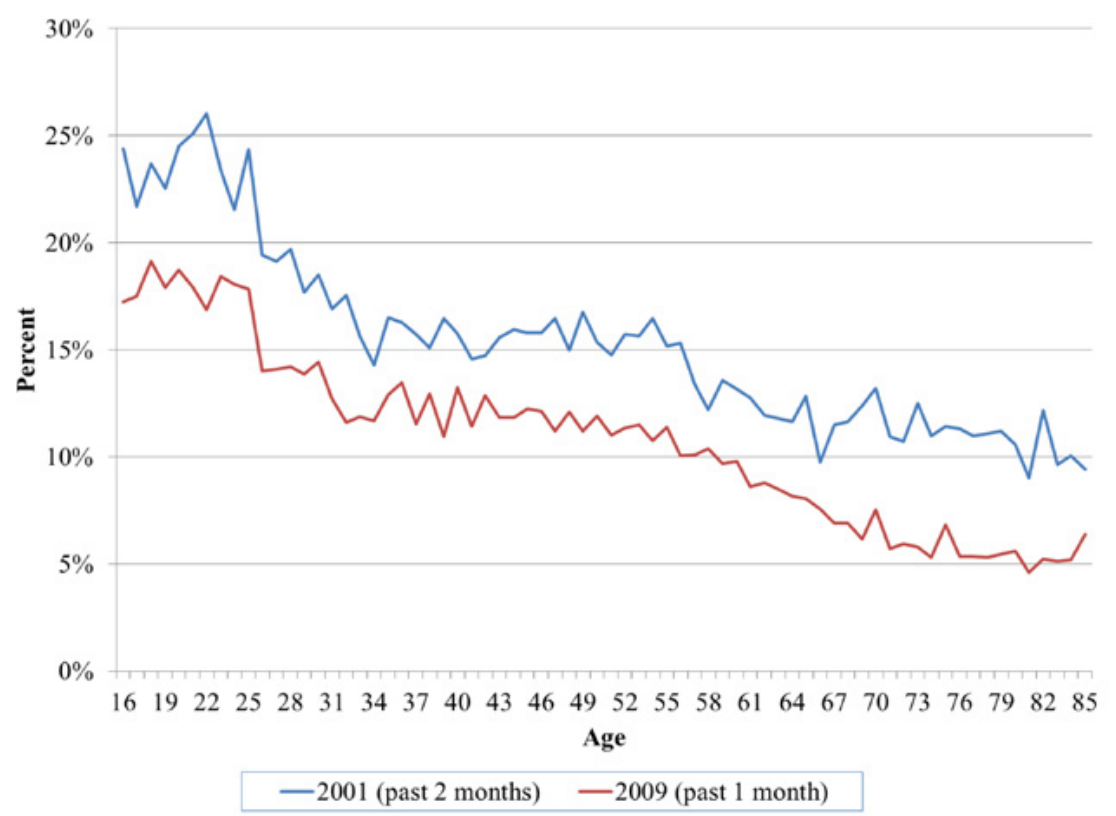

Source: NHTS, 2001 and 2009

${ }^{7}$ In 2009, fewer than $2 \%$ of older adults (ages $65+$ ) used transit on the survey day. 
What might explain higher transit use among younger adults relative to older adults? For one, lower average incomes tend to be associated with lower levels of automobile access (Pendyala, Kostyniuk, and Goulias 1995). Young adults, on average, are getting driver licenses at a later age than in previous decades (Taylor et al. 2013). And, finally, young adults are more likely to reside in central city, transit-rich neighborhoods (which may be related to both lower incomes and lower levels of automobile access). Nearly $20 \%$ of Millennials live in the 10 largest MSAs, which have the highest level of transit supply, compared to about $18 \%$ of older adults. As previously noted, urban living may be either a life cycle or cohort effect. If it is mostly a life cycle effect, whereby most urban young adults will "age out" of central-city, transit-rich neighborhoods, then higher levels of transit use are unlikely to persist as youth age through the life cycle; if it is a cohort effect, then transit use among younger riders is more likely to persist with age.

Finally, viewed together, Figures 3 and 4 reveal a fourth, and perhaps surprising, transit use pattern, which strongly suggests either a period or cohort effect on transit use. Transit use declined among all similar-age people between 2001 and 2009. It could be that the Great Recession depressed transit use among all ages in 2009 compared to 2001-a period effect-from which transit use across age cohorts may recover as the economy does. Or it could be that later generations of Americans use transit less than earlier generations did at the same age, which would not bode well for the transit in the future.

While suggestive, these descriptive data offer little insight on the independent effects of these relationships. To help untangle these relationships, a multivariate analysis was employed, as described below.

\section{Predicting Transit Use}

To better understand the factors driving transit use in the 2000s, logistic regression models were estimated to simultaneously account for an array of possible factors influencing transit use, including age and the role of birth-decade cohort, independent from other factors. One of the central purposes of this analysis was to determineafter controlling for other determinants of transit use-whether the underlying factors influencing travel are changing over time, and, in particular, if the next generation of American adults will be more or less likely to travel by public transit than previous generations.

Table 3 shows the results of two statistical models. Model 1 is a logistic regression model to predict the likelihood of taking transit on the survey day. Model 2 is a similar model to predict the likelihood of using transit in the prior month(s). ${ }^{8}$ After controlling for other factors thought to determine transit use, the cohort effect variables-birth decades-were found to be not statistically-significant predictors of transit use. More recent birth cohorts (younger generations) were no more or less likely to take public transit than older cohorts, with one exception-those born before 1960 were more likely to ride transit the previous month than the youngest generation.

${ }^{8}$ Recorded as within one month prior to survey in 2009 and two months prior to the 2001 survey. 
TABLE 3.

Factors Predicting Transit Use

\begin{tabular}{|c|c|c|c|c|c|c|}
\hline \multirow[b]{3}{*}{ Variables } & \multicolumn{3}{|c|}{$\begin{array}{l}\text { Model 1: } \\
\text { Made transit trip on survey day }\end{array}$} & \multicolumn{3}{|c|}{$\begin{array}{l}\text { Model 2: } \\
\text { Made transit trip in last month }\end{array}$} \\
\hline & \multicolumn{3}{|c|}{$n=392,175$} & \multicolumn{3}{|c|}{$n=392,175$} \\
\hline & Coef. & St. Error & Sig. & Coef. & St. Error & Sig. \\
\hline \multicolumn{7}{|l|}{ Individual Characteristics } \\
\hline Sex $($ Female $=1)$ & 0.04 & 0.05 & NS & -0.04 & 0.03 & NS \\
\hline Employed & 0.32 & 0.07 & $* * *$ & 0.13 & 0.03 & $* * *$ \\
\hline Student & 0.51 & 0.12 & $* * *$ & 0.47 & 0.06 & $* * *$ \\
\hline Age & -0.01 & 0.01 & $* *$ & -0.03 & 0.00 & $* * *$ \\
\hline \multicolumn{7}{|c|}{ Race/Ethnicity (Baseline: Non-Hispanic White) } \\
\hline Black & 0.96 & 0.08 & $* * *$ & 0.34 & 0.05 & $* * *$ \\
\hline Hispanic & 0.66 & 0.08 & $* * *$ & 0.13 & 0.05 & $* *$ \\
\hline Other & 0.65 & 0.09 & $* * *$ & 0.15 & 0.06 & $* *$ \\
\hline \multicolumn{7}{|c|}{ Birth Decade (Baseline 1980-1990) } \\
\hline 1910s-1940s & 0.07 & 0.25 & NS & 0.31 & 0.12 & $* *$ \\
\hline $1950 \mathrm{~s}$ & 0.16 & 0.18 & NS & 0.28 & 0.09 & $* * *$ \\
\hline $1960 \mathrm{~s}$ & 0.00 & 0.15 & NS & 0.03 & 0.08 & NS \\
\hline $1970 s$ & -0.08 & 0.12 & NS & -0.10 & 0.06 & NS \\
\hline \multicolumn{7}{|l|}{ Household Characteristics } \\
\hline Live w/kids & -0.30 & 0.08 & $* * *$ & -0.15 & 0.04 & $* * *$ \\
\hline Live w/parents & 0.08 & 0.13 & NS & 0.08 & 0.06 & NS \\
\hline Household Size & 0.11 & 0.03 & $* * *$ & 0.05 & 0.01 & $* * *$ \\
\hline Household Income $(\$ 10,000 s)$ & 0.06 & 0.01 & $* * *$ & 0.12 & 0.01 & $* * *$ \\
\hline Household Vehicle Count & -1.20 & 0.05 & $* * *$ & -0.79 & 0.02 & $* * *$ \\
\hline \multicolumn{7}{|l|}{ Neighborhood Characteristics } \\
\hline Transit supply & 0.04 & 0.02 & $* *$ & 0.14 & 0.02 & $* * *$ \\
\hline Transit supply*age & -0.00 & 0.00 & NS & -0.00 & 0.00 & NS \\
\hline Residential Density & 0.03 & 0.00 & $* * *$ & 0.14 & 0.01 & $* * *$ \\
\hline \multicolumn{7}{|l|}{ Year (Base: 2001) } \\
\hline 2009 & -0.08 & 0.07 & NS & 0.01 & 0.00 & NS \\
\hline Constant & -1.97 & 0.2 & $* * *$ & -16.46 & 8.3 & $* *$ \\
\hline
\end{tabular}

Note: Regression unit is person; sample: 16 years and older.

${ }^{* * *} p<0.01,{ }^{* *} p<0.05,{ }^{*} p<0.1$, NS is not statistically significant.

Source: 2001 and 2009 NHTS; EPA 2014

The models also showed that transit use declines with age, a life cycle effect.

Additionally, as expected, other life cycle variables had a clear association with transit use. Household composition plays an important role. Adults in households with children are less likely to use transit. This squares with previous research, which finds that households with children are more likely to have complex trip-making patterns that are difficult to accomplish on transit and for which households are more likely to drive (Hensher and Reyes 2000; McGuckin, Zmud, and Nakamoto 2005). In contrast, we found a positive relationship between household size and transit use. This relationship 
may be owing to competition among household members for automobiles; for example, Kitamura (1989) found that households with more drivers than cars take transit more than households with equal numbers of drivers and cars. Being a student also was positively related to transit use in both models. This finding is consistent with studies showing a positive relationship between students and transit use and ridership (Khattak et al. 2011; Taylor et al. 2009). Student status is associated with age; on average, students in the sample were 20.8 years old. The relationship between "student status" and transit use likely represents a life cycle effect, one that youth grow out of as they age. It is possible that once students become accustomed to using public transit, they may be more likely to continue using transit as they age (Fujii and Gärling 2005), although this would not explain why transit use is lowest among middle-aged cohorts, at least some of whom presumably rode transit in their younger student years.

Employment may be, in part, a life cycle effect, as it is inversely related to being a student. It was positively related to transit use on the survey day and during the previous month. Although period effects, such as a recession, may exert pressure on life cycle variables such as employment, employment represents an important life cycle transition from school into the workforce. Being a student has a stronger positive effect on transit use than employment, potentially helping to explain decreasing transit use with age.

Neighborhood residential density and transit richness may reflect either a cohort and/or a life cycle effect. This depends on whether youth choose to remain in dense, transit-rich areas or move out of them as they age. If the former, residential location could be interpreted as a cohort effect; if the latter, it acts as a life cycle effect.

Currently, Millennials living independently-i.e., without their parents-reside in denser neighborhoods, on average, compared to older adults. Young adults also are more likely to live in tracts with a slightly higher supply of transit compared to older adults (see Figure 5). Both variables—density and transit supply—are positively associated with

FIGURE 5.

Transit-rich neighborhoods and resident age, 2009
0.5

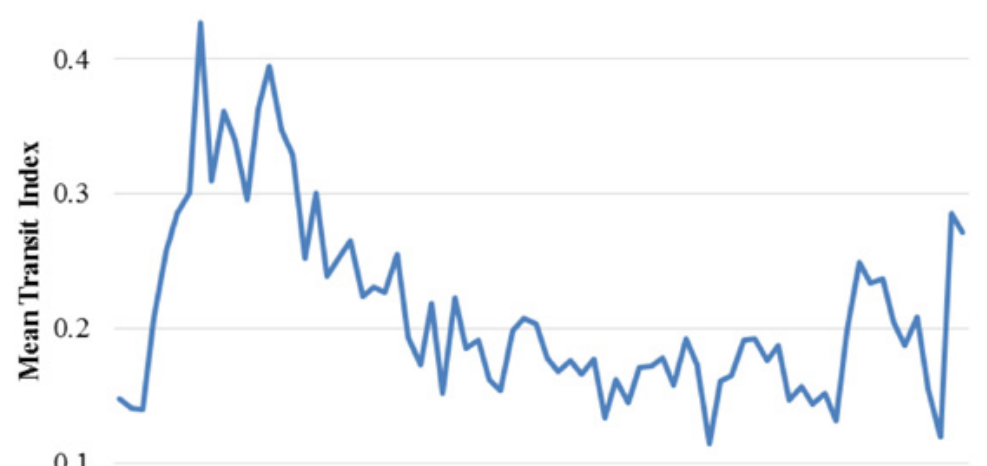

0.1

16192225283134374043464952555861646770737679828588

Age 
transit use in all three models. Since the quality of transit service affects all people in a given area and not just teens and young adults, the interaction between transit supply and cohort was tested to understand whether younger cohorts who live in transit-rich areas are more likely to use transit than older cohorts who also live in transit-rich areas. This interaction term was not significant in any of the models and was excluded from the final models. Therefore, the sustained increase in transit use and its relationship to the residential location of Millennials as they age is less about being more likely to ride transit in dense neighborhoods and more about if they will continue to live in dense neighborhoods as they age.

Period effects were not significant in either the survey day or within the past month(s) models. As a final test, whether there was an interaction between generational cohort and survey year was examined to assess if period effects varied across cohorts. These interaction terms were not statistically significant and, therefore, were excluded in the final model.

Finally, it is important to note that the Millennial generation is unique from previous generations in that, in particular, they are disproportionately Hispanic and non-white compared to older generations. Because Hispanic and non-white travelers are more likely to ride transit than are white travelers, transit use may rise with population growth and change. However, even within each race/ethnicity, age and birth decade are not significant predictors of transit use, and younger cohorts are not more likely to ride transit controlling for other factors. Therefore, if average transit use among Millennials remains high even as they age, this is likely more attributable to demographic transitions-a compositional effect-rather than an increasing preference for transit among those within various demographic groups.

These results should be interpreted with two caveats. First, only eight years elapsed between the 2001 and 2009 NHTS, which may be too short to observe lasting cohort effects. Second, the results are muddied by the Great Recession, which bottomed out in 2009. Although period effects were not statistically-significant in the model, the recession undoubtedly affected other variables that influence travel behavior such as employment and income. Future travel data will help to address both these caveats by including a longer sampling frame and post-recession travel data.

\section{Conclusion}

Although young adults are indeed more likely to ride public transit than older adults, little evidence was found in the data analyzed that these patterns reflect a waxing embrace of transit that may be expected to persist as teens and young adults age, as suggested by some observers. After controlling for factors such as age (a life cycle variable), employment and student status, race/ethnicity, income, household living situation, auto availability, and residential location, essentially no statistically-significant independent effects of generational birth cohort on transit use were observed. Transit use among young adults also does not appear to be directly related to period effects operationalized in this analysis as 2001 and 2009, although it is acknowledged that the period effects may be reflected in changes in other variables. 
These findings suggest that although young adults are more likely than older adults to ride transit, their higher use is due to (1) life cycle factors common among young people (such as being a student, not yet having children, having a lower income), (2) demographic factors (such as being a racial/ethnic minority), and (3) locational factors (such as living in densely-developed, transit-rich neighborhoods). It is possible that as the U.S. population continues to become more diverse and if racial/ethnic minorities continue to use transit more frequently than white riders as they age, then elevated levels of transit use may persist among these groups. But there is no guarantee of this; for example, research on travel among immigrants suggests that transit use declines with years living in the U.S. (Blumenberg and Smart 2011). Likewise, if younger adults remain in urban areas as they age, then these aging adults may remain loyal transit users. Although this is certainly possible, it is by no means guaranteed. In sum, this paper finds that although Millennials, on average, may express a greater preference for transit than members of older generations, these preferences do not manifest in transit use greater than what would otherwise be explained by factors unrelated to either age or generational status.

What do the findings regarding youth suggest for public transit in the years ahead? Governments large and small have made substantial financial commitments to expanding public transit service in recent years; both service levels and, especially, public expenditures have grown dramatically. In the first decade of the 21st century, inflationadjusted revenue vehicle miles of service increased by $34 \%$ and revenue vehicle miles by $29 \%$. Total public expenditures on transit service increased even faster during this time period-total inflation-adjusted transit capital and operating expenses rose by $72 \%$ overall and 58\% per passenger trip (APTA 2015b).

Although transit patronage was up during the 2000s, it rose at a far slower rate than either transit service or (especially) expenditures. Overall transit use was up 9\% during the decade and passenger miles of travel rose $1 \%$, both roughly the same as the increases in the U.S. population living in metropolitan areas-11\% (Wilson et al. 2012).

Despite increases in expressed preferences for public transit among youth and significant increases in transit service and public expenditures on the mode, per-capita transit ridership actually was down slightly $(-2 \%)$ during the 2000s. The national transit data presented in Table 4 square with the NHTS transit data examined in this analysis: between 2000 and 2009, the percentage of the population that rode transit on an average day dipped from 5.1 to $4.9 \%$ (NHTS 2001, 2009). ${ }^{9}$

\footnotetext{
${ }^{9}$ This change is not statistically significant at a $95 \%$ level of confidence.
} 
TABLE 4.

Transit Service and Ridership, 2000-2010

\begin{tabular}{|l|r|r|r|}
\hline \multicolumn{1}{|c|}{ Aggregate Statistics } & \multicolumn{1}{c|}{$\begin{array}{c}\mathbf{2 0 0 0} \\
\text { (in millions) }\end{array}$} & $\begin{array}{c}\text { 2010 } \\
\text { (in millions) }\end{array}$ & $\begin{array}{c}\text { Percent } \\
\text { Change }\end{array}$ \\
\hline Metropolitan population & 233 & 258 & $11 \%$ \\
\hline Unlinked passenger trips & 9,363 & 10,218 & $9 \%$ \\
\hline Passenger miles & 47,666 & 54,012 & $13 \%$ \\
\hline Vehicle revenue miles & 3,613 & 4,837 & $34 \%$ \\
\hline Vehicle revenue hours & 246 & 317 & $29 \%$ \\
\hline Total capital and operating expense* & $\$ 32,233$ & $\$ 55,579$ & $72 \%$ \\
\hline Adjusted Measures & & & \\
\hline Unlinked passenger trips per capita & 40.2 & 39.6 & $-2 \%$ \\
\hline Passenger miles per capita & 204.5 & 209.1 & $2 \%$ \\
\hline Passengers per vehicle revenue mile & 2.6 & 2.1 & $-19 \%$ \\
\hline Passengers per vehicle revenue hour & 38.1 & 32.2 & $-16 \%$ \\
\hline Capital and operating expense per passenger trip* & $\$ 3.44$ & $\$ 5.94$ & $58 \%$ \\
\hline
\end{tabular}

*Inflation adjusted to 2009 dollars.

Source: APTA 2015b; Wilson et al. 2012

Collectively, the data presented in Table 4 point to a recent renaissance in transit provision and expenditure, but not in transit use or, especially, service productivity. Further, the data analyzed in this study suggest that heightened levels of transit use among teens and young adults are far from assured to persist as they begin to age. In concert, these data suggest that transit agencies cannot count on Millennials to stem the recent declines in transit productivity on their own.

Instead, concerted efforts to motivate increased transit use and improve transit service attractiveness likely will be required to keep Millennials in the transit riding habit. Improving transit service frequency and reliability are common barriers to transit use among riders of all ages and are important to rider satisfaction (Beirão and Cabral 2007; Cain 2006; Yoh et al. 2011). Targeted transit investments that increase transit reliability and accessibility could make transit more adaptable to a wide variety of travelers and trips and, thus, be more amenable to life cycle changes such as increased trip chaining with the presence of children. Such improved transit service could enable Millennials to do what previous generations have not, and what Millennials themselves do not appear poised to do on their own, which is to continue to use transit as they age.

\section{References}

American Community Survey. 2008-2012. 5-Year American Community Survey.

American Public Transportation Association (APTA). 2012. 2012 Public Transportation Fact Book Appendix A: Historical Tables. www.apta.com.

APTA. 2013. Millennials \& Mobility. Understanding the Millennial Mindset. www.apta. com. http://www.apta.com/resources/statistics/Documents/FactBook/2015-APTAFact-Book-Appendix-A.pdf. 
APTA. 2015a. 2015 APTA Transit Fact Book. http://www.apta.com/resources/statistics/ Pages/transitstats.aspx.

APTA. 2015b. 2015 Public Transportation Fact Book, Appendix A Historical Tables. www. apta.com.

Ball, J. 2014. "The Proportion of Young Americans Who Drive Has Plummeted-and No One Knows Why." The New Republic, March 12.

Bamberg, S., I. Ajzen, and P. Schmidt. 2003. "Choice of Travel Mode in the Theory of Planned Behavior: The Roles of Past Behavior, Habit, and Reasoned Action." Basic and Applied Social Psychology, 25(3): 175-187.

Beirão, G., and J. S. Cabral. 2007. “Understanding Attitudes Towards Public Transport and Private Car: A Qualitative Study. Transport Policy, 14(6): 478-489.

Blumenberg, E., A. Brown, K. Ralph, B. D. Taylor, and C. T. Voulgaris. 2015. “Typecasting Neighborhoods and Travelers: Analyzing the Geography of Travel Behavior among Teens and Young Adults in the U.S http://tinyurl.com/obneh8w.

Blumenberg, E., and M. Smart. 2011. "Migrating to Driving: Exploring the Multiple Dimensions of Immigrants' Automobile Use." In Lucas, K., R. Weinberger, and E. Blumenberg, Auto Motives: Understanding Car Use Behaviours. Bingley, UK, Emerald: 225-252.

Blumenberg, E., B. D. Taylor, M. Smart, K. Ralph, M. Wander, and S. Brumbagh. 2012. "What's Youth Got to Do with It? Exploring the Travel Behavior of Teens and Young Adults." UCLA.

Cain, A. 2006. "Teenage Mobility in the United States: Issues and Opportunities for Promoting Public Transit." Transportation Research Record, 1971: 140-148.

Cortright, J. 2015. "Twenty-Somethings are Choosing Cities. Really." http:// cityobservatory.org/twenty-somethings-are-choosing-cities-really/.

Davis, B., T. Dutzik, and P. Baxandall. 2012. "Transportation and the New Generation: Why Young People are Driving Less and What It Means for Transportation Policy." http://www.ssti.us/wp/wp-content/uploads/2012/04/Transportation_and_the_ New_Generation.pdf.

Dittmar, H., and G. Ohland. 2004. The New Transit Town: Best Practices in TransitOriented Development. Island Press.

Dutzik, T., and P. Baxandall. 2013. "A New Direction: Our Changing Relationship with Driving and the Implications for America's Future." http://www.uspirg.org/sites/ pirg/files/reports/A\%20New\%20Direction\%20vUS.pdf.

Environmental Protection Agency. 2014. Smart Location Database. http://www2.epa. gov/smart-growth/smart-location-mapping.

Frank, L., M. Bradley, S. Kavage, J. Chapman, and T. K. Lawton. 2008. “Urban Form, Travel Time, and Cost Relationships with Tour Complexity and Mode Choice." Transportation, 35(1): 37-54. 
Fujii, S., and T. Gärling. 2005. "Temporary Structural Change: A Strategy to Break CarUse Habit and Promote Public Transport." Paper presented at the International Conference of Traffic and Transport Psychology.

Glaeser, E. L., M. E. Kahn, and J. Rappaport. 2008. “Why do the Poor Live in Cities? The Role of Public Transportation." Journal of Urban Economics, 63(1): 1-24.

Guest, A. M., and C. Cluett. 1976. "Analysis of Mass Transit Ridership Using 1970 Census Data." Traffic Quarterly, 30(1).

Hensher, D. A., and A. J. Reyes. 2000. "Trip Chaining as a Barrier to the Propensity to Use Public Transport." Transportation, 27(4): 341-361.

Inglis, J., and P. Baxandall. 2014. "Highway Boondoggles: Wasted Money and America's Transportation Future." http://www.uspirg.org/sites/pirg/files/reports/Highway Boondoggles USPIRG.pdf.

Khattak, A., X. Wang, S. Son, and P. Agnello. 2011. "Travel By University Students in Virginia: Is This Travel Different from Travel by the General Population?" Transportation Research Record, 2255: 137-145.

Kitamura, R. 1989. "A Causal Analysis of Car Ownership and Transit Use." Transportation, 16(2): $155-173$.

Kolko, J. 2015. "Why Millennials Are Less Urban than You Think." FiveThirtyEight Economics. http://fivethirtyeight.com/features/why-Millennials-are-less-urban-thanyou-think/.

KRC Research. 2015. "Millennial is a State of Mind - Zipcar 2015 Millennial Survey Results [Press release]. http://www.slideshare.net/Zipcar_PR/zipcar2015millennialmind-slideshare/1.

Malcolm, H. 2014. "Millennials Prefer Cities with Good Public Transit." USA Today, April 24.

McDonald, N. C. 2015. "Are Millennials Really the "Go-Nowhere" Generation? Journal of the American Planning Association, 81: 90-103.

McGuckin, N., J. Zmud, and Y. Nakamoto. 2005. "Trip-Chaining Trends in the United States: Understanding Travel Behavior for Policy Making." Transportation Research Record, 1917: 199-204.

NHTS. 2001. 2001 National Household Travel Survey. http://nhts.ornl.gov.

NHTS. 2009. 2009 National Household Travel Survey. http://nhts.ornl.gov.

Nielson. 2014. "Millennials - Breaking the Myths." http://www.nielsen.com/content/ dam/corporate/us/en/reports-downloads/2014 Reports/nielsen-millennial-reportfeb-2014.pdf.

Pendyala, R. M., L. P. Kostyniuk, and K. G. Goulias. 1995. "A Repeated Cross-Sectional Evaluation of Car Ownership." Transportation, 22(2): 165-184. 
Pew Research Center. 2010. "Millennials. A Portrait of Generation Next. Confident. Connected. Open to Change." http://www.pewsocialtrends.org/files/2010/10/ Millennials-confident-connected-open-to-change.pdf.

Ramsey, K., A. Bell. 2014. Smart Location Database. Version 2.0 User Guide. http://www2. epa.gov/sites/production/files/2014-03/documents/sld_userguide.pdf.

Rodríguez, D. A., J. Joo. 2004. "The Relationship between Non-Motorized Mode Choice and the Local Physical Environment." Transportation Research Part D: Transport and Environment, 9(2): 151-173.

Rosenbloom, S., G. J. Fielding. 1998. Transit Markets of the Future: The Challenge of Change. Transportation Research Board.

Santos, A., N. McGuckin, H. Y. Nakamoto, D. Gray, and S. Liss. 2011. Summary of Travel Trends: 2009 National Household Travel Survey. http://nhts.ornl.gov/2009/pub/stt. pdf.

Taylor, B. D., D. Miller, H. Iseki, and C. Fink. 2009. “Nature and/or Nurture? Analyzing the Determinants of Transit Ridership across U.S. Urbanized Areas." Transportation Research Part A: Policy and Practice, 43(1), 60-77.

Taylor, B. D., K. Ralph, E. Blumenberg, and M. Smart. 2013. “Who Knows About Kids These Days? Analyzing Determinants of Youth and Adult Mobility between 1990 and 2009." Paper presented at the Transportation Research Board 92nd Annual Meeting.

TransitCenter. 2014. “Who's On Board. Mobility Attitudes Survey.” http://transitcenter. org/ourwork/mobility-attitudes-survey/.

Thompson, D. 2015. “Not So Cheap, After All.” The Atlantic, April 21.

Urban Land Institute. 2015. "America in 2015. A ULI Survey of Views on Housing, Transportation, and Community." http://uli.org/wp-content/uploads/ULIDocuments/America-in-2015.pdf.

Urban Land Institute \& Belden Russonello Strategists (ULI/BRS). 2013. "Americans' Views on their Communities, Housing, and Transportation." http://www.uli.org/ wp-content/uploads/ULI-Documents/America-in-2013-Final-Report.pdf.

Wilson, S. G., D. A. Plane, P. J. Mackun, T. R. Fischetti, and J. Goworowska, J. 2012. "Patterns of Metropolitan and Micropolitan Population Change: 2000 to 2010." http://www.census.gov/prod/cen2010/reports/c2010sr-01.pdf.

Yoh, A., H. Iseki, M. Smart, and B. Taylor. 2011. "Hate to Wait: Effects of Wait Time on Public Transit Travelers' Perceptions." Transportation Research Record, 2216: 116-124. 


\section{About the Authors}

ANNE E. BRown (aebrown0316@ucla.edu) is an Urban Planning Ph.D. student at UCLA; her research focuses on travel behavior, transportation finance, and transportation and economic outcomes.

Evelyn BLumenberg (eblumenb@g.ucla.edu) is Professor and Chair of Urban Planning at the University of California, Los Angeles; her research focuses on access to opportunity among low-income households.

BRIAN D. TAYLOR (btaylor@g.ucla.edu) is Director of the Institute of Transportation Studies and Lewis Center for Regional Policy Studies at UCLA; his research centers on travel behavior, transportation finance, social equity, and public transit.

KELCIE RALPH (kelcie.r@gmail.com) is an Assistant Professor in the Bloustein School of Planning and Public Policy at Rutgers; her research centers on travel behavior, bicycling, and environmental policy.

CAROLe TURLey Voulgaris (caroleturley@ucla.edu) is an Urban Planning Ph.D. student at UCLA, where she studies transportation planning and funding decisionmaking and its influence on individual and household travel behavior. 